\title{
Head-to-head comparison of the cardio-ankle vascular index between patients with acute coronary syndrome and stable angina pectoris
}

\author{
Akinori Sairaku ${ }^{1}$, Shin Eno $^{1}$, Tatsuya Hondo ${ }^{1}$, Hiroki Teragawa ${ }^{2}$, Yukiko Nakano ${ }^{3}$, Keiji Matsuda ${ }^{1}$, \\ Tomohiko Kisaka ${ }^{1}$ and Yasuki Kihara ${ }^{3}$
}

We aimed to evaluate whether there was a difference in the arterial stiffness assessed by the cardio-ankle vascular index (CAVI) between patients with acute coronary syndrome (ACS) and those with stable angina pectoris (SAP). A total of 199 consecutive patients, 79 with ACS and 120 with SAP, who underwent emergency or elective coronary revascularization were enrolled. The CAVI was measured within 2 days after the procedures, and was compared between the ACS and SAP patients. As parameters related to arteriosclerosis, carotid intima-media thickness (IMT) and number of stenotic coronary vessels were also evaluated. Although IMT was significantly greater in SAP patients ( $2.1 \pm 1.1$ vs. $2.4 \pm 0.9 ; P=0.022)$, CAVI was significantly higher in ACS patients $(10.0 \pm 1.7$ vs. $9.3 \pm 1.3 ; P=0.0012)$. After an adjustment for the clinical parameters with a significant difference between the two patient groups, CAVI remained significantly higher in ACS patients than in SAP patients (odds ratio $1.92,95 \%$ confidence interval 1.30-3.02; $P=0.0023)$. A multiple linear regression analysis revealed that age $(\beta=0.44 ; P<0.0001)$ and ACS $(\beta=0.3 ; P<0.0001)$ were the independent determinants of CAVI. A significant decrease in CAVI was observed at 6 months of follow-up as compared with the acute phase in 18 patients with ACS $(10.9 \pm 1.6$ vs. $10.0 \pm 1.5 ; P=0.019)$. In conclusion, CAVI was significantly and independently higher in patients with ACS than in those with SAP, which might result from a transient increase in the CAVI caused by acute myocardial ischemia. Hypertension Research (2010) 33, 1162-1166; doi:10.1038/hr.2010.141; published online 12 August 2010

Keywords: acute coronary syndrome; arterial stiffness; CAVI; stable angina pectoris

\section{INTRODUCTION}

Recently, a novel arterial stiffness parameter called the cardio-ankle vascular index (CAVI) has been developed that is independent of blood pressure and differs from pulse wave velocity. ${ }^{1,2}$ The CAVI is significantly associated with the parameters related to atherosclerosis $^{3-7}$ furthermore, it is positively correlated with the severity of coronary artery disease. ${ }^{5,6}$ However, there are few reports on CAVI in patients with acute coronary syndrome (ACS) requiring emergency revascularization.

Increased arterial stiffness has been shown to be an independent predictor of cardiovascular events and mortality in high-risk populations. $^{8-11}$ In addition, the aortic stiffness assessed by invasive methods is also a powerful and independent risk factor for recurrent acute coronary events in patients with coronary artery disease (CAD), including stable angina pectoris (SAP). ${ }^{12}$ Hence, we hypothesized that the arterial stiffness assessed by CAVI in ACS patients would be significantly higher than that in SAP patients. The aim of our study was to evaluate whether there was a difference in CAVI between patients with ACS and those with SAP.

\section{METHODS}

Study population

Between July 2007 and March 2009, A total of 199 consecutive patients (age $71 \pm 11$ years, 138 men) with ACS $(n=79)$, defined as an acute ST- or nonST-segment elevation myocardial infarction or Braunwald's class IIIB unstable angina pectoris, and SAP $(n=120)$ were enrolled. An emergency percutaneous coronary intervention or coronary artery bypass grafting was performed in patients with ACS and an elective percutaneous coronary intervention or coronary artery bypass grafting was performed in those with SAP.

Patients with hypotension, systolic blood pressure (SBP) $\leqslant 90 \mathrm{~mm} \mathrm{Hg}$, cardiac decompensation, a previous myocardial infarction, a history of coronary revascularization and peripheral arterial disease with an anklebrachial pressure index of $<0.9$ were excluded.

The study was approved by the local ethics committees, and all subjects gave their written informed consent.

\section{CAVI measurement}

CAVI was measured according to the methods described previously. ${ }^{1,2}$ Briefly, patients were placed in the supine position and their electrocardiogram and heart sounds were monitored. Pulse wave velocity was obtained by dividing

${ }^{1}$ Department of Cardiology, Chugoku Workers Compensation Hospital, Kure, Japan; ${ }^{2}$ Department of Cardiovascular Medicine, Hiroshima General Hospital of West Japan Railway Company, Hiroshima, Japan and ${ }^{3}$ Department of Cardiovascular Medicine, Hiroshima University Hospital, Hiroshima, Japan

Correspondence: Dr A Sairaku, Department of Cardiovascular Medicine, Hiroshima University Hospital, 1-2-3 Kasumi, Minaki-ku, Hiroshima 734-8551, Japan.

E-mail: rjrgw059@ybb.ne.jp

Received 3 February 2010; revised 10 June 2010; accepted 14 June 2010; published online 12 August 2010 
vascular length by the time taken for the pulse wave to propagate from the aortic valve to the ankle. Thereafter, blood pressure was measured at the brachial artery. CAVI was calculated by the following equation: $\mathrm{CAVI}=a\left(\{2 \rho \times 1 /(\mathrm{SBP}-\mathrm{DBP})\} \times\left\{\operatorname{In}(\mathrm{SBP} / \mathrm{DBP}) \times \mathrm{PWV}^{2}\right\}\right)+b$, where SBP is the systolic blood pressure, DBP is the diastolic blood pressure, $\rho$ is the density of blood and $a$ and $b$ are constants. All measurements and calculations were made automatically using a VaSera VS-1000 (Fukuda Denshi, Tokyo, Japan). CAVI was measured within 2 days after coronary revascularization in all patients, and at a 6-month follow-up in 18 patients with ACS and in 21 with SAP. A preliminary evaluation of CAVI without CAD was conducted in 30 patients who had an intact coronary artery demonstrated by coronary angiography.

\section{Carotid IMT measurement}

The carotid arteries were evaluated with high-resolution B-mode ultrasonography (HD11XE, PHILIPS, Tokyo, Japan). ${ }^{13}$ One longitudinal image of the common carotid artery and three longitudinal images of the internal carotid artery were acquired. The carotid intima-media thickness (IMT) was measured as the distance between the lumen-intima interface and the media-adventitia interface on the B-mode. Atherosclerotic lesions were defined as plaques when the thickness of the intima-media complex was $\geqslant 1.1 \mathrm{~mm}$. The maximal IMT was used for analysis.

\section{Echocardiography}

Echocardiography was performed using B- and M-mode ultrasonography (SEQUOIA C256, SIEMENS, Tokyo, Japan). The left ventricular (LV) enddiastolic diameter, maximal left atrial diameter and end-diastolic thickness of the ventricular septum were measured. The LV end-diastolic and end-systolic volumes (EDV and ESV) were calculated from the apical two- and fourchamber views using a modified Simpson's method. Thereafter, the LV ejection fraction $(\mathrm{LVEF})$ was calculated as $\mathrm{LVEF}=(\mathrm{EDV}-\mathrm{ESV}) / \mathrm{EDV} \times 100$

\section{Assessment of the severity of CAD}

Coronary angiography was performed according to the standard methods before percutaneous coronary intervention or coronary artery bypass grafting. Significant stenosis was defined as narrowing of $\geqslant 75 \%$ in any of the three major coronary branches or $\geqslant 50 \%$ in the left main trunk artery. The severity of $\mathrm{CAD}$ was assessed on the basis of the number of stenotic coronary vessels. If there was stenosis in the left main trunk artery, we diagnosed it as two-vessel disease.

\section{Coronary risk factors and laboratory parameters}

We recorded the following traditional coronary risk factors: (1) diabetes mellitus (a fasting plasma glucose level $\geqslant 126 \mathrm{mg} \mathrm{dl}^{-1}$ and hemoglobin Alc $\geqslant 6.5 \%$, or the use of oral antidiabetic agents or insulin); (2) dyslipidemia (low-density lipoprotein-cholesterol $\geqslant 140 \mathrm{mg} \mathrm{dl}^{-1}$ or high-density lipoprotein-cholesterol $<40 \mathrm{mg} \mathrm{dl}^{-1}$ or triglyceride $\geqslant 150 \mathrm{mg} \mathrm{dl}^{-1}$ or the use of lipidlowering drugs); (3) hypertension (SBP $\geqslant 140 \mathrm{~mm} \mathrm{Hg}$ or DBP $\geqslant 90 \mathrm{~mm} \mathrm{Hg}$ or the use of antihypertensive agents); and (4) smoking history (previous or current cigarette smoking).

At baseline, the following measurements related to arteriosclerosis risk were evaluated: body mass index, estimated glomerular filtration rate, ${ }^{14}$ lipid profile, fasting plasma glucose level and hemoglobin Alc. In addition, C-reactive protein was measured on the day after the procedures. In ACS patients, the peak serum creatine kinase level was determined by measurements taken every $3 \mathrm{~h}$ after the procedures.

\section{Statistical analysis}

Statistical analyses were performed using JMP software version 5.1 (SAS Institute Japan, Tokyo). The clinical characteristics of the study subjects were presented using frequencies for categorical variables and means with s.d.'s for continuous variables. The differences between the two patient groups were examined using Pearson's $\chi^{2}$-tests for categorical variables or $t$-tests for continuous variables. Correlations between CAVI and other clinical parameters were assessed by Pearson's correlation test. Subsequently, significantly correlated variables were further analyzed using a multiple linear regression analysis to assess their independent relationship with CAVI. A multiple logistic regression analysis was performed using the variables found to be significant in the univariate comparisons and age to assess whether there was a significant difference in CAVI between the two patient groups. For all analyses, a $P$-value of $<0.05$ was considered statistically significant.

\section{RESULTS}

In ACS patients $(n=79)$, there were 67 patients who had an ST-segment elevation myocardial infarction, four who had a non-ST segment elevation myocardial infarction and eight who had an unstable angina pectoris. The number of patients who underwent a coronary artery bypass grafting was 4 in ACS patients and 11 in SAP patients $(n=120)$.

The prevalence of hypertension (54 vs. 83\%; $P<0.0001$ ), SBP $(123 \pm 19$ vs. $134 \pm 17 ; \quad P<0.0001)$, LVEF $(55 \pm 10$ vs. $63 \pm 13$; $P<0.0001)$, IMT $(2.1 \pm 1.1$ vs. $2.4 \pm 0.9 ; P=0.022)$ and triglyceride (110 \pm 58 vs. $150 \pm 99 ; P=0.0018)$, as well as the frequency of the use

Table 1 Clinical characteristics of the subjects with ACS and SAP

\begin{tabular}{lccc}
\hline & ACS & SAP & P-value \\
\hline$n$ & 79 & 120 & \\
Age (years) & $69 \pm 1.2$ & $72 \pm 1.0$ & 0.13 \\
Male & $57(72 \%)$ & $81(68 \%)$ & 0.49 \\
Systolic blood pressure (mm Hg) & $123 \pm 19$ & $134 \pm 17$ & $<0.000$ \\
Diastolic blood pressure (mm Hg) & $75 \pm 12$ & $78 \pm 11$ & 0.11 \\
Body mass index $\left(\mathrm{kg} \mathrm{m}^{-2}\right)$ & $23.5 \pm 3.9$ & $24.5 \pm 3.7$ & 0.08
\end{tabular}

$\begin{array}{lrrc}\text { Traditional coronary risk factors } & & & \\ \quad \text { Diabetes mellitus } & 33(42 \%) & 54(45 \%) & 0.41 \\ \text { Hypertension } & 43(54 \%) & 100(83 \%) & <0.0001 \\ \text { Dyslipidemia } & 42(53 \%) & 79(66 \%) & 0.063 \\ \quad \text { Smoking } & 37(47 \%) & 56(47 \%) & 0.98 \\ \text { No. of coronary risk factors } & 1.8 \pm 0.9 & 2.1 \pm 1.0 & 0.056 \\ \text { No. of stenotic coronary vessels } & 1.4 \pm 0.7 & 1.6 \pm 0.7 & 0.067 \\ \text { Left ventricular ejection fraction (\%) } & 55 \pm 10 & 63 \pm 13 & <0.0001 \\ \text { Inter ventricular septum thickness (mm) } & 10.4 \pm 2.1 & 10.7 \pm 1.7 & 0.24 \\ \text { Left atrium diameter (mm) } & 37.2 \pm 5.7 & 38.7 \pm 6.8 & 0.13 \\ \text { Intima media thickness (mm) } & 2.1 \pm 1.1 & 2.4 \pm 0.9 & 0.022 \\ \text { Cardio-ankle vascular index } & 10.0 \pm 1.7 & 9.3 \pm 1.3 & 0.0012\end{array}$

$\begin{array}{lrrl}\text { Laboratory measurement } & & & \\ \text { Triglyceride }\left(\mathrm{mg} \mathrm{dl}^{-1}\right) & 110 \pm 58 & 150 \pm 99 & 0.0018 \\ \text { LDL-cholesterol }\left(\mathrm{mg} \mathrm{dl}^{-1}\right) & 103 \pm 30 & 112 \pm 36 & 0.07 \\ \text { HDL-cholesterol }\left(\mathrm{mg} \mathrm{dl}^{-1}\right) & 50 \pm 15 & 53 \pm 15 & 0.1 \\ \text { Fasting plasma glucose }\left(\mathrm{mg} \mathrm{dl}^{-1}\right) & 134 \pm 45 & 125 \pm 45 & 0.17 \\ \text { Hemoglobin A1c (\%) } & 6.2 \pm 1.5 & 6.2 \pm 1.4 & 0.86 \\ \text { Estimated glomerular filtration rate } & 65 \pm 16 & 64 \pm 18 & 0.64 \\ \text { (mg dl }^{-1} \text { per min) } & & & \\ \text { C-reactive protein }\left(\mathrm{mg} \mathrm{dl}^{-1}\right) & 3.1 \pm 4.5 & 0.6 \pm 1.2 & <0.0001 \\ \text { Peak creatine kinase } & 2647 \pm 2261 & & \end{array}$

$\begin{array}{lccc}\text { Medications } & & & \\ \text { Antihypertensive agents } & 36(46 \%) & 90(75 \%) & <0.0001 \\ \text { ACE inhibitors/ARBs } & 25(32 \%) & 47(39 \%) & 0.28 \\ \text { Calcium channel blockers } & 21(27 \%) & 58(48 \%) & 0.0019 \\ \text { Diuretics } & 5(6 \%) & 28(23 \%) & 0.0016 \\ \alpha / \beta \text { blockers } & 6(8 \%) & 17(14 \%) & 0.16 \\ \text { Statins } & 8(10 \%) & 47(39 \%) & <0.0001 \\ \text { Oral antidiabetic agents/insulin } & 14(18 \%) & 24(20 \%) & 0.69\end{array}$

Abbreviations: ACE, angiotensin converting enzyme; ACS, acute coronary syndrome; $A R B$, angiotensin II receptor blocker; HDL, high-density lipoprotein; LDL, low-density lipoprotein; SAP, stable angina pectoris. 
of antihypertensive agents ( $46 v s .75 \% ; P<0.0001)$ and that of statins (10 vs.39\%; $P<0.0001$ ), was significantly lower in ACS patients than in SAP patients. Meanwhile, CAVI $(10.0 \pm 1.7$ vs. $9.3 \pm 1.3 ; P=0.0012)$ and C-reactive protein $(3.1 \pm 4.5$ vs. $0.6 \pm 1.2 ; P<0.0001)$ were significantly higher in ACS patients as compared with SAP patients (Table 1).

According to the preliminary evaluation of CAVI in the 30 subjects without CAD (age $67 \pm 11$ years, 20 men, 12 (40\%) had hypertension, $5(17 \%)$ diabetes, $4(13 \%)$ dyslipidemia and $6(20 \%)$ were current smokers), CAVI was significantly lower than that in patients with ASC or SAP ( $8.6 \pm 1.8 v s$. ACS; $P<0.0001$ vs. SAP; $P=0.0002)$.

In the univariate analysis, hypertension $(r=0.36 ; P=0.0016)$, smoking $(r=0.23 ; P=0.048)$, IMT $(r=0.36 ; P=0.0031)$, estimated glomerular filtration rate $(r=0.45 ; P<0.0001)$ and antihypertensive agents $(r=0.29 ; P=0.012)$ were significantly correlated with CAVI in ACS patients, and body mass index $(r=0.3 ; P=0.0014)$ was a significant correlate in SAP patients. Age was the only factor that was significantly related to CAVI in the univariate and multivariate linear regression analyses in both patient groups $(r=0.66 ; P<0.0001$, $\beta=0.56 ; P<0.0001$ in ACS patients, $r=0.31 ; P=0.0007, \beta=0.23$; $P=0.013$ in SAP patients). In all patients, ACS emerged as an independent determinant of CAVI $(\beta=0.3 ; P<0.0001)$, as well as age $(\beta=0.44 ; P<0.0001)$. In ACS patients, there was no significant correlation between CAVI and $\operatorname{LVEF}(r=0.12 ; P=0.32)$ or peak serum creatine kinase level $(r=0.13 ; P=0.26)$ (Table 2).

A multiple regression analysis revealed that ACS patients had a significantly higher CAVI as compared with SAP patients (odds ratio 1.92, 95\% confidence interval $1.30-3.02 ; P=0.0023$ ) after an adjustment for age, hypertension, SBP, IMT, LVEF, triglyceride, C-reactive protein, antihypertensive agents and statins (Figure 1).

The CAVI measured at the 6-month follow-up was significantly decreased compared with that measured within 2 days after coronary revascularization in 18 patients with ACS (10.9 \pm 1.6 vs. $10.0 \pm 1.5$; $P=0.019$; mean follow-up period $200 \pm 33$ days), although their hemodynamic status and medications prescribed remained unchanged. In contrast, in 21 patients with SAP who were followed up, CAVI was significantly increased in the chronic phase as compared with the acute phase $(9.2 \pm 1.4$ vs. $9.9 \pm 1.3 ; P=0.022$; mean follow-up period $220 \pm 44$ days).

\section{DISCUSSION}

This study demonstrated that CAVI was significantly higher in patients with ACS as compared with those with SAP. We also found that the CAVI of patients with ACS in the acute phase significantly decreased in

Table 2 Correlations between the CAVI and clinical parameters

\begin{tabular}{|c|c|c|c|c|c|c|c|c|c|c|c|c|}
\hline & \multicolumn{4}{|c|}{$\operatorname{ACS}(\mathrm{n}=79)$} & \multicolumn{4}{|c|}{$\operatorname{SAP}(\mathrm{n}=120)$} & \multicolumn{4}{|c|}{$A C S+S A P(\mathrm{n}=199)$} \\
\hline & \multicolumn{2}{|c|}{ Univariate } & \multicolumn{2}{|c|}{ Multivariate $^{\mathrm{a}}$} & \multicolumn{2}{|c|}{ Univariate } & \multicolumn{2}{|c|}{ Multivariate $^{\mathrm{b}}$} & \multicolumn{2}{|c|}{ Univariate } & \multicolumn{2}{|c|}{ Multivariate $^{c}$} \\
\hline & r & P-value & $\beta$ & P-value & r & P-value & $\beta$ & $\mathrm{P}$-value & r & $\mathrm{P}$-value & $\beta$ & P-value \\
\hline Age & 0.66 & $<0.0001$ & 0.56 & $<0.0001$ & 0.31 & 0.0007 & 0.23 & 0.013 & 0.47 & $<0.0001$ & 0.44 & $<0.0001$ \\
\hline Male & 0.18 & 0.12 & & & 0.18 & 0.052 & & & 0.024 & 0.75 & & \\
\hline Acute coronary syndrome & & & & & & & & & 0.23 & 0.0011 & 0.3 & $<0.0001$ \\
\hline Systolic blood pressure & 0.19 & 0.095 & & & 0.037 & 0.15 & & & 0.037 & 0.61 & & \\
\hline Diastolic blood pressure & 0.11 & 0.36 & & & 0.11 & 0.25 & & & 0.072 & 0.33 & & \\
\hline Body mass index & 0.064 & 0.59 & & & 0.3 & 0.0014 & -0.22 & 0.018 & 0.21 & 0.004 & -0.045 & 0.55 \\
\hline Diabetes mellitus & 0.11 & 0.35 & & & 0.11 & 0.24 & & & 0.098 & 0.18 & & \\
\hline Hypertension & 0.36 & 0.0016 & 0.25 & 0.036 & 0.14 & 0.14 & & & 0.048 & 0.51 & & \\
\hline Dyslipidemia & 0.18 & 0.13 & & & 0.057 & 0.54 & & & 0.13 & 0.075 & & \\
\hline Smoking & 0.23 & 0.048 & 0.18 & 0.09 & 0.049 & 0.61 & & & 0.065 & 0.38 & & \\
\hline No. of coronary risk factors & 0.026 & 0.82 & & & 0.016 & 0.87 & & & 0.013 & 0.86 & & \\
\hline No. of stenotic coronary vessels & 0.094 & 0.42 & & & 0.025 & 0.79 & & & 0.0014 & 0.98 & & \\
\hline Left ventricular ejection fraction & 0.12 & 0.32 & & & 0.017 & 0.85 & & & 0.13 & 0.07 & & \\
\hline Inter-ventricular septum thickness & 0.0096 & 0.94 & & & 0.12 & 0.23 & & & 0.07 & 0.37 & & \\
\hline Left atrium diameter & 0.16 & 0.21 & & & 0.076 & 0.46 & & & 0.13 & 0.11 & & \\
\hline Intima-media thickness & 0.36 & 0.0031 & 0.093 & 0.35 & 0.13 & 0.22 & & & 0.19 & 0.014 & 0.11 & 0.12 \\
\hline Triglyceride & 0.15 & 0.21 & & & 0.11 & 0.25 & & & 0.16 & 0.029 & 0.072 & 0.35 \\
\hline LDL-cholesterol & 0.12 & 0.3 & & & 0.069 & 0.47 & & & 0.11 & 0.14 & & \\
\hline HDL-cholesterol & 0.19 & 0.11 & & & 0.069 & 0.47 & & & 0.095 & 0.2 & & \\
\hline Fasting plasma glucose & 0.13 & 0.27 & & & 0.098 & 0.3 & & & 0.13 & 0.75 & & \\
\hline Hemoglobin A1c & 0.18 & 0.15 & & & 0.077 & 0.47 & & & 0.12 & 0.12 & & \\
\hline Estimated glomerular filtration rate & 0.45 & $<0.0001$ & -0.17 & 0.15 & 0.076 & 0.42 & & & 0.22 & 0.0019 & -0.0042 & 0.96 \\
\hline C-reactive protein & 0.052 & 0.7 & & & 0.036 & 0.7 & & & 0.079 & 0.31 & & \\
\hline Peak serum creatine kinase & 0.13 & 0.26 & & & & & & & & & & \\
\hline Antihypertensive agents & 0.29 & 0.012 & 0.012 & 0.92 & 0.077 & 0.41 & & & 0.031 & 0.67 & & \\
\hline Statins & 0.045 & 0.7 & & & 0.019 & 0.84 & & & 0.07 & 0.34 & & \\
\hline Oral antidiabetics/insulin & 0.078 & 0.51 & & & 0.1 & 0.27 & & & 0.082 & 0.26 & & \\
\hline
\end{tabular}

Abbreviations: ACS, acute coronary syndrome; CAVI, cardio-ankle vascular index; HDL, high-density lipoprotein; LDL, low-density lipoprotein; $r$, Pearson's correlation coefficient; SAP, stable angina pectoris; $\beta$, standardized coefficient.

pectoris; $\beta$, standardized
aAdjusted $R^{2}=0.47$.

aAdjusted $R^{2}=0.47$
bAdjusted $R^{2}=0.12$

bAdjusted $R^{2}=0.12$.
cAdjusted $R^{2}=0.25$. 


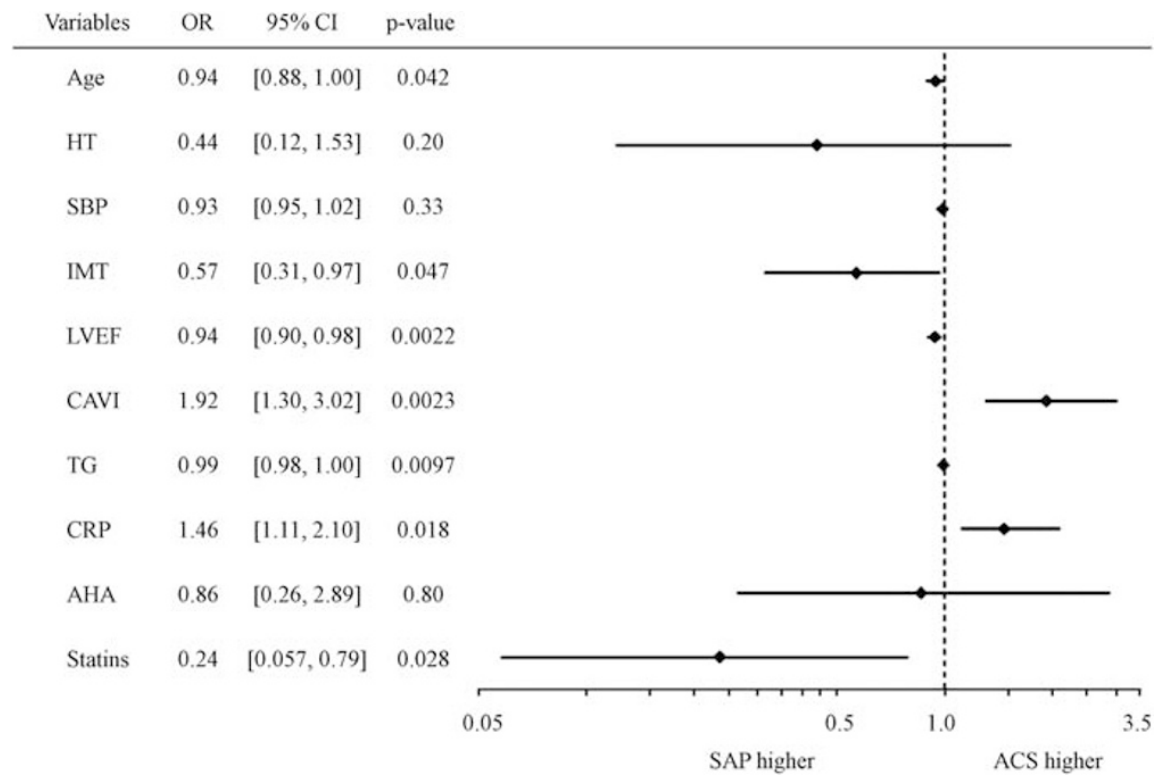

Figure 1 Multivariate odds ratio estimates of the clinical predictors of ACS vs. SAP. AHA, antihypertensive agent; CAVI, cardio-ankle vascular index; CRP, C-reactive protein; HT, hypertension; IMT, intima-media thickness; LVEF, left ventricular ejection fraction; SBP, systolic blood pressure; TG, triglyceride.

the chronic phase. This result may suggest a transient increase in CAVI caused by acute myocardial ischemia. The possible mechanisms of the transient increase in CAVI were assumed to be as follows: (1) It is reported that severe myocardial ischemia induces LV diastolic dysfunction ahead of LV systolic dysfunction. ${ }^{15,16} \mathrm{LV}$ diastolic dysfunction is associated with an increased CAVI. ${ }^{7,17-19}$ Thus, the ACS patients, who would have an abrupt and severe myocardial ischemia, could have a higher CAVI than SAP patients. (2) Systemic acute inflammation and an elevated level of interleukin-18 are strongly associated with increased arterial stiffness. ${ }^{20,21}$ Therefore, as the level of interleukin-18 is higher in ACS patients than in SAP patients, ${ }^{22}$ arterial stiffness could be increased in ACS patients compared with SAP patients. (3) The nitric oxide synthase inhibitor, asymmetric dimethylarginine, increases the arterial stiffness. ${ }^{23}$ Thus, because the level of asymmetric dimethylarginine in patients with unstable angina pectoris is significantly higher than that in patients with $\mathrm{SAP},{ }^{24}$ arterial stiffness could be increased more in ACS patients than in SAP patients. These factors associated with acute myocardial ischemia may solely and/or multifactorially contribute to the increase in CAVI in ACS patients.

CAVI, an arterial stiffness parameter, is known to increase parallel to the progression of the carotid arterial thickness. ${ }^{3-6}$ However, despite having a lower IMT, ACS patients had a rather higher CAVI compared with SAP patients. This discrepancy may be explained by the transient increase in CAVI observed in ACS patients. That is, as a reflection of the cardiovascular condition in the acute phase of an abrupt episode of myocardial ischemia, CAVI may increase as we have demonstrated, whereas IMT would not to be affected by the transient change in the cardiovascular condition. This difference in response to the transient change in the cardiovascular condition may be related in part to the fact that CAVI is a physiological parameter, whereas IMT is a morphological one.

We observed more variables with a significant correlation to CAVI in the univariate analysis in ACS patients than in SAP patients, and among those variables, age was the only variable that was associated with CAVI in both patient groups. Furthermore, as many studies have reported, ${ }^{3-6,17}$ it was the strongest predictor variable of CAVI in the multivariate linear regression analysis in both patient groups. The result that ACS was another strong independent determinant of CAVI in the entire study group highlights the significant increase in CAVI in ACS patients as compared with SAP patients.

In ACS patients, there was no correlation between CAVI and LVEF, which may support the results of the previous studies that were conducted on subjects with a normal LV systolic function. ${ }^{18,19}$ Furthermore, CAVI was not associated with the peak creatine kinase level in ACS patients. These results may suggest that CAVI would not be directly affected by the myocardial infarct size.

Several studies have shown that statins, pioglitazone and antihypertensive agents, including angiotensin-converting enzyme inhibitors, angiotensin II receptor blockers and calcium channel blockers, decrease the arterial stiffness assessed by CAVI. ${ }^{25-28}$ However, although the frequency of use of these medications differed in the two groups in this study, no significant correlation between CAVI and the frequency of use of these medications was observed in the entire study group. Possible explanations for this result are that (1) as the majority of our study subjects were taking at least one of these medications, the interindividual variability of the effect of those medications on CAVI might have been small, (2) this study differed from previous studies $^{25-28}$ in that all our study subjects had significant CAD and several coronary risk factors, which might have resulted in an even smaller favorable effect on arterial stiffness with such medications in this study as compared with previous studies.

Our study had several limitations. First, it was a single-center study with a small number of patients, and furthermore, the number of patients who underwent a follow-up measurement of CAVI was even smaller. Second, we did not enroll any patients with any peripheral artery disease with an ankle-brachial pressure index of $<0.9$, because the CAVI in those patients was reported to show inaccurate data. ${ }^{2}$ Third, the prognosis of patients with a transient increase in CAVI was not shown in this study.

Despite these limitations, to the best of our knowledge, this is the first study on CAVI in ACS patients. In addition, our finding of a 
transient increase in CAVI observed in the patient with ACS provided new insight into the pathological vascular condition of acute myocardial ischemia. As several investigators have reported, an increased arterial stiffness is an independent predictor of cardiovascular events and mortality in subjects with coronary risk factors. ${ }^{8-11}$ Therefore, patients with a transient increase in arterial stiffness caused by acute myocardial ischemia should be followed up with extreme caution. To establish the clinical importance of measuring CAVI in ACS patients, large-scale prospective studies on the relationship between CAVI and prognosis in patients who have experienced ACS would be required.

In conclusion, CAVI was significantly higher in patients with ACS than in those with SAP independent of any other parameters related to arteriosclerosis, which might result from the transient increase in CAVI caused by acute myocardial ischemia.

\section{CONFLICT OF INTEREST}

The authors declare no conflict of interest.

\section{ACKNOWLEDGEMENTS}

We thank Mr Junichi Ugumori, Mr Shiro Hiura and the other staff in the clinical laboratory of Chugoku Workers Compensation Hospital for the measurements of CAVI and ultrasonography, and Dr Kenji Goto (Fukuyama Cardiovascular Hospital, Fukuyama, Japan) for his useful comments on this paper.

1 Yambe T, Yoshizawa M, Saijo Y, Yamaguchi T, Shibata M, Konno S, Nitta S, Kuwayama T. Brachio-ankle pulse wave velocity and cardio-ankle vascular index (CAVI). Biomed Pharmacother 2004; 58: S95-S98.

2 Shirai K, Utino J, Otsuka K, Takata M. A novel blood pressure-independent arterial wall stiffness parameter; cardio-ankle vascular index (CAVI). J Atheroscler Thromb 2006; 13: 101-107.

3 Kadota K, Takamura N, Aoyagi K, Yamasaki H, Usa T, Nakazato M, Maeda T, Wada M, Nakashima K, Abe K, Takeshima F, Ozono Y. Availability of cardio-ankle vascular index (CAVI) as a screening tool for atherosclerosis. Circ J 2008; 72: 304-308.

4 Okura T, Watanabe S, Kurata M, Manabe S, Koresawa M, Irita J, Enomoto D, Miyoshi K, Fukuoka T, Higaki J. Relationship between cardio-ankle vascular index (CAVI) and carotid atherosclerosis in patients with essential hypertension. Hypertens Res 2007; 30: $335-340$.

5 Nakamura K, Tomaru T, Yamamura S, Miyashita Y, Shirai K, Noike H. Cardio-ankle vascular index is a candidate predictor of coronary atherosclerosis. Circ J 2008; 72 : 598-604.

6 Izuhara M, Shioji K, Kadota S, Baba O, Takeuchi Y, Uegaito T, Mutsuo S, Matsuda M. Relationship of cardio-ankle vascular index (CAVI) to carotid and coronary arteriosclerosis. Circ J 2008; 72: 1762-1767.

7 Takaki A, Ogawa H, Wakeyama T, Iwami T, Kimura M, Hadano Y, Matsuda S, Miyazaki Y, Hiratsuka A, Matsuzaki M. Cardio-ankle vascular index is superior to brachial-ankle pulse wave velocity as an index of arterial stiffness. Hypertens Res 2008; 31: 1347-1355.

8 Laurent S, Boutouyrie P, Asmar R, Gautier I, Laloux B, Guize L, Ducimetiere P, Benetos A. Aortic stiffness is an independent predictor of all-cause and cardiovascular mortality in hypertensive patients. Hypertension 2001; 37: 1236-1241.

9 Shoji T, Emoto M, Shinohara K, Kakiya R, Tsujimoto Y, Kishimoto H, Ishimura E, Tabata T, Nishizawa Y. Diabetes mellitus, aortic stiffness, and cardiovascular mortality in endstage renal disease. J Am Soc Nephrol 2001; 12: 2117-2124.

10 Wang KL, Cheng HM, Sung SH, Chuang SY, Li CH, Spurgeon HA, Ting CT, Najjar SS, Lakatta $\mathrm{EG}$, Yin $\mathrm{FC}$, Chou $\mathrm{P}$, Chen $\mathrm{CH}$. Wave reflection and arterial stiffness in the prediction of 15-year all-cause and cardiovascular mortalities. A community-based study. Hypertension 2010; 55: 799-805.

11 Shoji T, Maekawa K, Emoto M, Okuno S, Yamakawa T, Ishimura E, Inaba M, Nishizawa Y. Arterial stiffness predicts cardiovascular death independent of arterial thickness in a cohort of hemodialysis patients. Atherosclerosis 2010; 210: 145-149.

12 Stefanadis C, Dernellis J, Tsiamis E, Stratos C, Diamantopoulos L, Michaelides A, Toutouzas P. Aortic stiffness as a risk factor for recurrent acute coronary events in patients with ischaemic heart disease. Eur Heart J 2000; 21: 390-396.

13 Handa N, Matsumoto M, Maeda H, Hougaku H, Ogawa S, Fukunaga R, Yoneda S, Kimura K, Kamada T. Ultrasonic evaluation of early carotid atherosclerosis. Stroke 1990; 21 : 1567-1572.

14 Poggio ED, Nef PC, Wang X, Greene T, Van Lente F, Dennis VW, Hall PM. Performance of the Cockcroft-Gault and modification of diet in renal disease equations in estimating GFR in ill hospitalized patients. Am J Kidney Dis 2005; 46: 242-252.

15 Williamson BD, Lim MJ, Buda AJ. Transient left ventricular filling abnormalities (diastolic stunning) after acute myocardial infarction. Am J Cardiol 1990; 66: 897-903.

16 Ishii K, Suyama T, Imai M, Maenaka M, Yamanaka A, Makino Y, Seino Y, Shimada K, Yoshikawa J. Abnormal regional left ventricular systolic and diastolic function in patients with coronary artery disease undergoing percutaneous coronary intervention: clinical significance of post-ischemic diastolic stunning. J Am Coll Cardiol 2009; 54: 1589-1597.

17 Sakane K, Miyoshi T, Doi M, Hirohata S, Kaji Y, Kamikawa S, Ogawa H, Hatanaka K, Kitawaki T, Kusachi S, Yamamoto K. Association of new arterial stiffness parameter, the cardio-ankle vascular index, with left ventricular diastolic function. J Atheroscler Thromb 2008; 15: 261-268.

18 Masugata H, Senda S, Okuyama H, Murao K, Inukai M, Hosomi N, Yukiiri K, Nishiyama A, Kohno M, Goda F. Comparison of central blood pressure and cardio-ankle vascular index for association with cardiac function in treated hypertensive patients. Hypertens Res 2009; 32: 1136-1142.

19 Mizuguchi Y, Oishi Y, Tanaka H, Miyoshi H, Ishimoto T, Nagase N, Oki T. Arterial stiffness is associated with left ventricular diastolic function in patients with cardiovascular risk factors: early detection with the use of cardio-ankle vascular index and ultrasonic strain imaging. J Card Fail 2007; 13: 744-751.

20 Vlachopoulos C, Dima I, Aznaouridis K, Vasiliadou C, loakeimidis N, Aggeli C, Toutouza M, Stefanadis C. Acute systemic inflammation increases arterial stiffness and decreases wave reflections in healthy individuals. Circulation 2005; 112 : 2193-2200.

21 Trøseid M, Seljeflot I, Weiss TW, Klemsdal TO, Hjerkinn EM, Arnesen H. Arterial stiffness is independently associated with interleukin-18 and components of the metabolic syndrome. Atherosclerosis 2010; 209: 337-339.

22 Mallat Z, Henry P, Fressonnet R, Alouani S, Scoazec A, Beaufils P, Chvatchko Y, Tedgui A. Increased plasma concentrations of interleukin-18 in acute coronary syndromes. Heart 2002; 88: 467-469.

23 Kielstein JT, Donnerstag F, Gasper S, Menne J, Kielstein A, Martens-Lobenhoffer J, Scalera F, Cooke JP, Fliser D, Bode-Böger SM. ADMA increases arterial stiffness and decreases cerebral blood flow in humans. Stroke 2006; 37: 2024-2029.

24 Jiang DJ, Cao Y, Xin HY, Li XH, Luo ZQ, Li YJ. Asymmetric dimethylarginine induces tissue factor expression in monocytes via NF-kappaB-dependent pathway: role in acute coronary syndromes. Atherosclerosis 2009; 205: 554-560.

25 Miyashita Y, Saiki A, Endo K, Ban N, Yamaguchi T, Kawana H, Nagayama D, Ohira M, Oyama T, Shirai K. Effects of olmesartan, an angiotensin II receptor blocker, and amlodipine, a calcium channel blocker, on Cardio-Ankle Vascular Index (CAVI) in type 2 diabetic patients with hypertension. J Atheroscler Thromb 2009; 16: 621-626.

26 Sasaki H, Saiki A, Endo K, Ban N, Yamaguchi T, Kawana H, Nagayama D, Ohhira M, Oyama T, Miyashita Y, Shirai K. Protective effects of efonidipine, a T- and L-type calcium channel blocker, on renal function and arterial stiffness in type 2 diabetic patients with hypertension and nephropathy. J Atheroscler Thromb 2009; 16: 568-575.

27 Miyashita Y, Endo K, Saiki A, Ban N, Yamaguchi T, Kawana H, Nagayama D, Ohira M, Oyama T, Shirai K. Effects of pitavastatin, a 3-hydroxy-3-methylglutaryl coenzyme a reductase inhibitor, on cardio-ankle vascular index in type 2 diabetic patients. J Atheroscler Thromb 2009; 16: 539-545.

28 Harashima K, Hayashi J, Miwa T, Tsunoda T. Long-term pioglitazone therapy improves arterial stiffness in patients with type 2 diabetes mellitus. Metabolism 2009; 58: 739-745. 